\title{
Genotype x Environment interaction, stability, and adaptability in progenies of Eucalyptus uro- phylla S.T. BLAKE using the AMMI model
}

\author{
S. Pupin', P. H. M. Silva ${ }^{2,3,4}$, F. A. Piotto ${ }^{4}$, A. C. Miranda5, D. U. G. Zaruma ${ }^{3}$, A. M. Sebbenn ${ }^{6}$, and M. L. \\ T. Moraes ${ }^{1}$
}

\author{
${ }^{1}$ Faculdade de Engenharia de Ilha Solteira / Universidade Estadual Paulista / UNESP, CP 31, CEP 15385-000, Ilha Solteira, \\ SP, Brazil \\ ${ }^{2}$ Instituto de Pesquisa e Estudos Florestais / IPEF, CEP 13415-000, Piracicaba, SP, Brazil \\ ${ }^{3}$ Faculdade de Ciências Agronômicas / Universidade Estadual Paulista / UNESP, CP 237, CEP 18603-970, Botucatu, SP, \\ Brazil \\ ${ }^{4}$ Escola Superior de Agricultura "Luiz de Queiroz" / Universidade de São Paulo / USP, CP 9, CEP 13418-900, Piracicaba, SP, \\ Brazil \\ ${ }^{5}$ Suzano Papel e Celulose, CP 63, CEP 45930-000, Mucuri, BA, Brazil \\ ${ }^{6}$ Instituto Florestal de São Paulo, CP 1322, CEP 01059-970, São Paulo, SP, Brazil,
}

Corresponding author: Silvelise Pupin, E-mail: silvelise.pupin@gmail.com

\begin{abstract}
One of the determinant factors in the success of breeding programs that aim to select genotypes for different geographical regions is understanding the interaction between genotypes and environments (GxE). The objectives of this study were to evaluate GxE interaction, stability, and adaptability, and determine the need for environmental stratification of open pollinated progenies of Eucalyptus urophylla. Five progeny tests were established in study areas with different environmental conditions in southeast and mid-west Brazil. We used a complete randomized block experimental design with 138 to 167 progenies, and variations in the numbers of replicates and plants per plot. The trait measured was diameter at breast height (DBH) at two years of age and the AMMI method was used to determine patterns of GxE interaction. Significant effects were detected for genotypes, environments, and for GxE interaction. The effect of environment was responsible for the greatest proportion of the phenotypic variation, followed by the effect of genotypes and GxE interaction. Some progenies with greater productivity and stability were identified, although stability is not associated with productivity. The stratification of the selection in three specific environments is necessary due to the occurrence of a complex GxE interaction.
\end{abstract}

Keywords: : Biplot analysis, eucalypts, forest breeding, stability

\section{Introduction}

Eucalyptus urophylla belongs to a group known as the "Big Nine", which are the nine most cultivated species of the genus in the world (Harwood, 2011). The species is recommended for tropical and subtropical climate regions, as either pure stands or as hybrid combinations (Hodge and Dvorak, 2015). The characteristics of the species include high productivity and wood quality, moderate resistance to water deficit, and tolerance to pests and disease (Assis et al., 2015). As such, it can be planted in areas that are unfavorable for other eucalypt species (Scanavaca Junior and Garcia, 2003).

The success of genetic improvement programs relies on the selection of productive genotypes. This selection requires an understanding of the interaction between genotypes and environments (GxE) in order to minimize or exploit their effects and increase efficiency in genotype selection. Selection is usually based on growth traits, which present a complex pattern of inheritance, making it difficult to predict the responses of genotypes to different environments (Namkoong et al., 1966). Information about the nature and magnitude of this interaction are fundamental, particularly for the selection of characteristics with low heritability (Yan and Kang, 2002).

Although the environmental effect represents $80 \%$ or more of variation, the effects of genotypes and the interaction between the two are the most relevant for selection (Yan and Kang, 2002). The GxE interaction reduces the correlation between phenotype and genotype (Rao et al., 2011) and interferes in genetic gains, which can create difficulties in selection. GxE interaction is one of the major challenges in plant breeding, 
especially since it occurs across a diversity of soil and climatic conditions (Vencovsky et al., 2012).

In order to study GxE interactions, it is necessary to establish multi-environment experimental networks (Mustapha et al., 2014). The assessment of interaction in multiple environments can result in the adoption of two different selection strategies: i) stratification of heterogeneous areas in smaller and homogeneous sub-regions for selection; or ii) selection of stable genotypes based on performance in a variety of environments (Adebola et al., 2013; Funga et al., 2017). In order to estimate the GxE interaction, several statistical techniques have been used, including univariate, multivariate, mixed and nonparametric methods (Akbarpour et al., 2014). The least effective method among them to capture the patterns of GxE interaction are those based on analysis of variance and linear regression (Correia et al., 2010). On the other hand, multivariate techniques can be effective tools to study interaction, such as those that include biplots: Additive Main effects and Multiplicative Interaction (AMMI) and Genotype main effects and GxE interaction effects (GGE) (Li et al., 2017).

Gauch (2006) suggests that only one of these methodologies should be used and emphasizes the superiority of AMMI analyses in terms of visualization. Using this method, we obtain two biplot graphs. AMMI1 demonstrates the additive effects on the $\mathrm{X}$ axis (genotype means and environments) and the first multiplicative interaction axis, the Interaction Principal Component Analysis (IPCA), on the $\mathrm{Y}$ axis. Genotypes with scores similar to zero are stable. Genotypes to the right have higher productivity than the general mean of the measured trait. Grouped genotypes show similar adaptation and groups located near to an environment are similarly influenced by that environment. The second graph, AMMI2, plots the IPCA1 and IPCA2. Genotypes and environments located away from the source contribute to interaction and those with IPCA1 and IPCA2 scores close to zero are stable. When the points occupy the same quadrant in the graph the genotype and environment interact positively and when they are located on opposite quadrants, they interact negatively. Specific adaptation can be identified when the genotype shows positive interaction and high productivity in one environment (Funga et al., 2017). The AMMI model has been widely used for crop species (Akter et al., 2014), although less so for forest species (Chambel et al., 2005; Li et al., 2017).

The objectives of this study were to evaluate GxE interaction, stability, and adaptability using AMMI analysis, and determine the need for environmental stratification of open pollinated progenies of $E$. urophylla.

\section{Materials and Methods}

This study included the evaluation of five trials of open pollinated progenies of $E$. urophylla. The germplasm belongs to the Cooperative Program for Forest Improvement (PCMF) of the Institute of Research and Forest Studies (IPEF) and it is representative of the genetic material widely used in Brazil. Progeny tests were established from 2009 to 2010 in five experimental areas: Anhembi and Itatinga, São Paulo State, belonging to the Department of Forestry Sciences, ESALQ/USP; Selvíria, Mato Grosso do Sul State, belonging to the Teaching, Research, and Extension Farm, FEPE-FEIS/UNESP; and Itamarandiba and Uberaba, Minas Gerais State, at the Aperam and Duratex forestry companies affiliated with PCMF. At each site, we recorded experimental and soil-climatic characteristics pertinent to the environment (Table 1). Management (soil tillage, fertility, weed control, and control of leaf-cutting ants and termites) followed commercial recommendations for each region (Gonçalves et al., 2013). The exception was in Selvíria where mineral fertilization was not used.

Table 1

Characteristics of the sites in which the five progeny tests were established

\begin{tabular}{lccccc}
\hline & Anhembi, SP & Itatinga, SP & Itamarandiba, MG & Uberaba, MG & Selvíria, MS \\
\hline Spacing $(\mathrm{m})$ & $3.0 \times 2.0$ & $3.0 \times 2.0$ & $3.0 \times 2.0$ & $3.0 \times 2.0$ & $3.0 \times 2.5$ \\
Repetition & 4 & 4 & 4 & 8 & 5 \\
Trees/Plot & 6 & 6 & 6 & 5 & 5 \\
Latitude & $22^{\circ} 28^{\prime}$ & $23^{\circ} 13^{\prime}$ & $17^{\circ} 45^{\prime}$ & $19^{\circ} 18^{\prime}$ & $20^{\circ} 21^{\prime}$ \\
Longitude & $48^{\circ} 07^{\prime}$ & $48^{\circ} 34^{\prime}$ & $42^{\circ} 46^{\prime}$ & $48^{\circ} 01^{\prime}$ & $51^{\circ} 24^{\prime}$ \\
Altitude $(\mathrm{m})$ & 472 & 827 & 910 & 850 & 375 \\
Soil & $\mathrm{NQ}$ & LVAd & LVA & LAc & LVd \\
Climate & $\mathrm{Aw}$ & $\mathrm{Cwa}$ & $\mathrm{CWa}$ & $\mathrm{Aw}$ & $\mathrm{Aw}$ \\
A.A.T. $\left({ }^{\circ} \mathrm{C}\right)$ & 21.8 & 19.7 & 22.6 & 22.6 & 24.8 \\
A.A.P. $(\mathrm{mm})$ & 1300 & 1372 & 1100 & 1474 & 1309 \\
\hline
\end{tabular}

A.A.T.: average annual temperature; A.A.P.: average annual precipitation; NQ: Typic Quartzipisamment; LVAd: Dystrophic Red-Yellow Latosol; LVA: Red-Yellow Latosol; LAc: Typical Acrylic Yellow Latosol; LVd: Typical Dystrophic Red Latosol. Aw: tropical climate with dry winter; Cwa: humid temperate climate with dry winter and hot summer.

We used a randomized block statistical design for the progeny tests with varying numbers of progenies in each environment (138 to 167). To extract a subset and balance the experimental data for use in the AMMI method (Yan et al., 2011), we discarded about $25 \%$ of all genotypes. A total of 126 progenies were measured for diameter at breast height $(\mathrm{DBH}, \mathrm{cm})$ at two years of age. The choice of DBH as the measured trait is due to its correlation with volume, one of the main quantitative traits used in breeding programs (Martinez et al., 2012), and the measurement of DBH is highly accurate and easily obtained during data collection.

For the joint analysis of progeny tests and GxE evaluation, we used the AMMI method, combining two statistical procedures: analysis of variance (ANOVA) and singular value decomposition (SVD). The first decomposes the additive effects of genotypes and environments and the second partitions the multiplicative effects of the interaction of the main components (IPCA). The AMMI uses a linear model and treats the main and interaction effects as fixed (Crossa et al., 2012). The statistical model used follows Gauch and Zobel (1997):

$$
Y_{i j}=\mu+g_{i}+e_{j}+\sum_{k=1}^{n} \lambda_{k} \gamma_{i k} \alpha_{j k}+\rho_{i j}+\varepsilon_{i j}
$$


where: $Y_{i j}$ is the mean response of genotype $i$ in environment $j$; $\mu$ is the overall mean: $g_{i}$ is the fixed effect of genotype $i ; e_{j}$ is the fixed effect of environment $j ; \lambda_{k}$ is the square root of the k-th eigenvalues of the matrices, (Tu) (Tu)' or (Tu)' (Tu), of equal nonzero eigenvalues, where (tu) $=\left[\widehat{\boldsymbol{\tau}}_{\boldsymbol{i j}}\right]$ is the interaction matrix obtained as the residual of the adjustment to the matrices main effects, by analysis of variance, applied to the matrix of means; $\gamma_{i k}$ is the $i$-th element (related to the factor $\tau$ ) of the k-th eigenvector of (tu) (tu); $a_{j k}$ is the j-th element (related to the factor $\mathrm{U}$ ) of the $\mathrm{k}$-th eigenvector of (TU), (Tu); $\rho_{i j}$ is the noise present in the data; $\varepsilon_{i j}$ is the mean experimental error; $i$ is the genotype variations, $i=(1,2, \ldots, g) ; j$ is the variations of environments, $j$ $=(1,2, \ldots, \mathrm{e})$; and $p$ is the non-zero root of the characteristic, $p=$ $(1,2, \ldots, \min (g-1, e-1))$. The analyses were carried out using the software R 3.2.0 (R Development Core Team, 2017) with the statistical packages „agricolae“ (Mendiburu, 2013), „klaR“ (Weihs et al., 2005), and "plotrix" (Lemon, 2006). Statistical significance of the main components (IPCA) was obtained using the F-test described by Gollob (1968).

\section{Results}

Significant effects ( $\mathrm{Pr}<0.001)$ were detected for genotypes, environments, and the GxE interaction (Table 2). The effect of environment was responsible for the greatest proportion of total mean square $(96.1 \%)$, followed by the effect of genotypes and GxE interaction. The sum of squares of the interaction (SSGXE) was partitioned into four main component axes (IPCA): the first two were significant based on Gollob's test and explained $65.9 \%$ of GxE variation (Table 2).

Table 2

Analysis of variance and decomposition of the GxE interaction of the principal components (IPCA) for the DBH trait in the five progeny tests.

\begin{tabular}{lccccc}
\hline $\begin{array}{c}\text { Source of } \\
\text { variation }\end{array}$ & $\mathrm{df}$ & $\mathrm{MS}$ & $\operatorname{Pr}$ & Exp. (\%) & Ac. (\%) \\
\hline Genotype & 125 & 138.3 & $<0.001$ & - & - \\
Environmental & 4 & 13812.5 & $<0.001$ & - & - \\
G×E & 500 & 24.6 & $<0.001$ & - & - \\
IPCA 1 & 128 & 33.9 & $<0.001$ & 37.8 & 37.8 \\
IPCA 2 & 126 & 25.5 & $<0.001$ & 28.1 & 65.9 \\
IPCA 3 & 124 & 17.8 & & 19.3 & 85.2 \\
IPCA 4 & 122 & 13.9 & & 14.8 & 100.0 \\
Block (A) & 20 & 287.1 & $<0.001$ & - & - \\
Error & 16612 & 14.4 & - & - & - \\
\hline df is the degrees of freedom; MS is the mean square; Pr is the probability of the test; Exp. \\
is the percentage of variance explanation; Ac. is the accumulated percentage.
\end{tabular}

Biplot AMMI1 captured $90.6 \%$ of the Sum of Squares (SS), including main effects, GxE interaction, and the IPCA1. In general, the distribution of the progenies on the axis in the abscissa was sparse, while the distribution in the ordinate was more concentrated. These results indicate that the progenies present more variability in productivity than in stability (Figure 1).
Itamarandiba was the only stable environment and Selvíria was the least stable environment. Of the $126 \mathrm{E}$. urophylla progenies evaluated in the five environments, $53.2 \%$ (67) were considered stable (IPCA1 near zero), suggesting that they did not contribute to the complex GxE interaction. The environments in Anhembi, Itatinga, and Uberaba showed positive interaction with 60 progenies, but less than $50 \%$ of these sites presented productivity above the mean DBH (Figure 1).

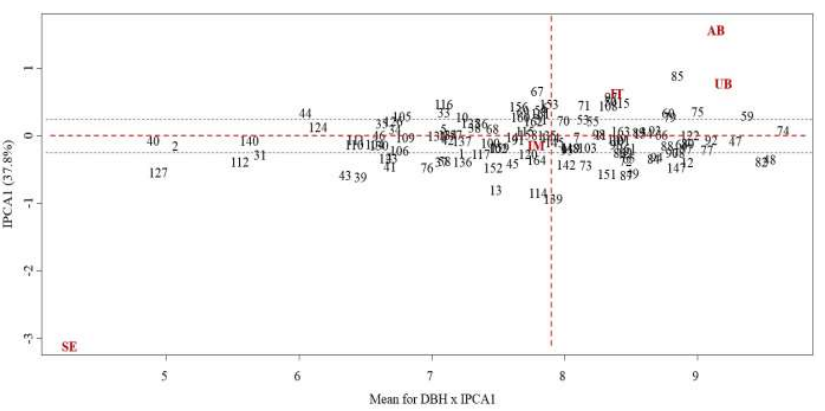

Figure 1

Biplot AMMI1 (Means for DBHXIPCA1) for 126 Eucalyptus urophylla progenies evaluated in five environments: Anhembi, SP (AB); Itamarandiba, MG (IM); Itatinga, SP (IT); Selvíria, MS (SE); and Uberaba, MG (UB).

Biplot AMMI2 shows the first two axes that concentrate the effects of the GxE interaction: IPCA1 and IPCA2. The environments in Itatinga and Itamarandiba had the least interactive effect on the progenies, as shown through the short length of the projections. Acute angles between projections means greater similarity in the response of the GxE interaction. As the angles between Uberaba and Itatinga and Uberaba and Itamarandiba were acute, the ranking of progenies do not vary widely among these environments. The lack of correlation was verified among the other pairs of sites with angles of approximately $90^{\circ}$ (Figure 2 ).

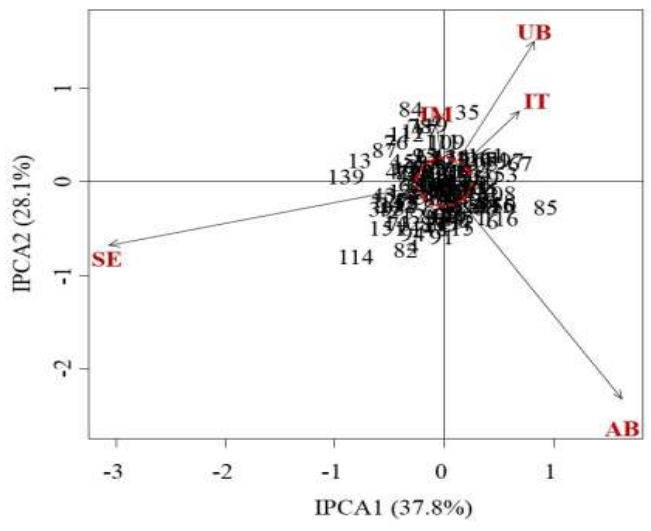

Figure 2

Biplot AMMI2 (IPCA1 $\times$ IPCA2) for productivity represented by DBH in 126 Eucalyptus urophylla progenies tested in five environments: Anhembi, SP (AB); Itatinga, SP (IT); Itamarandiba, MG (IM); Uberaba, MG (UB); and Selvíria, MS (SE). 


\section{Discussion}

The effects due to environmental variation was lower than the 80 \% reported by Yan and Kang (2002); however, the environment produced more pronounced effects than the other effects, as indicated by Gauch (2006). Thus, the effects of environment and its interaction with genotypes should not be neglected in breeding programs.

The results indicate divergence among the tested environments with a difference in growth of more than twice the DBH at two years after planting; the lowest level of growth was in Selvíria (mean DBH $=4.3 \mathrm{~cm}$ ) and the highest in Uberaba $(9.2$ $\mathrm{cm})$. This difference is largely due to the fact that mineral fertilization, which is fundamental for eucalypt growth in the first years after planting (Gonçalves et al., 2013; Silva et al., 2013; Melo et al., 2015), was not used in Selvíria.

The significant effects for genotype indicates genetic variation in relation to $\mathrm{DBH}$, which can be further capitalized in breeding programs. The means among progenies ranged from 4.9 (40) to $9.7 \mathrm{~cm}(74)$, indicating a wide variability in performance. For almost $40 \%$ of progenies, growth is within the range expected and similar to the results obtained by Pinto et al. (2014) and Nunes et al. (2016) for clones of E. urophylla and Eucalyptus sp., respectively, at three years of age.

The detected significant effects for the GxE interaction indicate that progeny responses vary in different environments (complex interaction), thus underscoring the need to analyze stability and adaptability to distinguish groups of genotypes adapted to several specific conditions and/or environments. Pupin et al. (2015) found significant GxE interaction for DBH at two years of age for the same set of E. urophylla progenies in these same five environments. In this previous study, the mean obtained was different and the Anhembi environment showed better performance in relation to the other study sites (10.5 $\mathrm{cm}$ ). It is possible that the genotypes that contributed to a greater mean may have been excluded from the AMMI analysis in order to balance the data.

In the analysis of variance, the main additive effects (environments and genotypes) and the multiplicative effect of the interaction were decomposed and the first two axes were significant, indicating that the GxE interaction was concentrated in IPCA 1 and IPCA2. The first two IPCA axes explain most of the variation of GxE (Table 2), although less than the $70 \%$ discussed by Crossa et al. (1991). However, the AMMI method does not seek to recover $100 \%$ of the $\mathrm{SS}_{\mathrm{Gx} \mathrm{E}^{\prime}}$ but rather the proportion most influenced by the effects of genotypes and environments, thus discarding the so-called noise (Duarte and Vencovsky, 1999). This was observed herein as the sum of squares of the IPCAs do not equal the total, leaving a small proportion of noise (6.8\%) consisting of unpredictable and uninterpretable responses (Verrissimo et al., 2012). Similar results were obtained by Mitrovic et al. (2012) and Akter et al. (2014) for annual crops. In these cases, the main feature of AMMI is the ability to capture the majority of the patterns in the first IPCA axes (Crossa et al., 1991).

In proportional terms, the first two IPCAs represent the largest portion of the $\mathrm{SS}_{\mathrm{GXE}}(61.4 \%)$, with $50.8 \%$ of degrees of freedom. In yield trials of soybeans, Zobel et al. (1988) captured $71.0 \%$ of $\mathrm{SS}_{\mathrm{GXE}}$ with only $19 \%$ of degrees of freedom, indicating that the AMMI model summarized the dataset much more effectively than in the current study.

Biplot AMMI1 indicates that many progenies are stable (Figure 1) although not necessarily productive; that is, stability is not related to productivity. The only stable environment identified in the present study was Itamarandiba. The mean $\mathrm{DBH}$ was slightly below the general average $(7.78 \mathrm{~cm}<7.90$ $\mathrm{cm})$, indicating that this environment is suitable for the expression of the genetic potential of the progenies. In progeny trials of Pinus radiata, for DBH at 6 to 10 years, Ivković et al. (2015) observed a correlation of the GxE interaction with climatic variables, mainly temperature and precipitation. In our case, levels of rainfall lower than the annual average during the study years may have caused the stability in Itamarandiba (2010= $965 \mathrm{~mm} ; 2011=915 \mathrm{~mm}$; annual historic average of $1100 \mathrm{~mm}$ ) (Inmet, 2017). Similarly, E. grandis families in Itamarandiba, under moderate and prolonged water stress, showed lower productivity levels of the stand and reduced environmental effects on the variation of the phenotype (Silva et al., 2018). Genotype management in a stable environment is more reliable since the genotype ranking will be determined primarily by genotypic effects (Duarte and Vencovsky, 1999). The least stable environment was Selvíria and the mean DBH was well below the other studied environments $(4.3 \mathrm{~cm})$. In Selvíria, the rate of survival was also low (54\%) and this was likely the result of limited silvicultural management. That is, the absence of adequate management contributed to an increase in unpredictable and uncontrolled conditions that augment the effects of the GxE interaction (Vencovsky and Barriga, 1992).

Although more than half of E. urophylla progenies presented predicable behavior, for selection and recommendation of genotypes, stability should be associated with productivity (Figure 1 ). Therefore, 32 progenies (25.4\%) can be considered stable and productive, presenting favorable traits for selection and recommendation due to the simple GxE interaction for these progenies. These results are similar to those observed for E. grandis progenies in five experiments established between latitudes $08089^{\prime}$ to $32^{\circ} 10^{\prime}$ in Brazil and Uruguay (Silva et al., 2018).

Anhembi, Itatinga, and Uberaba showed positive GxE interaction, with 24 genotypes identified as the most productive and stable, which could form a select set of genotypes adapted to these environments (Figure 1). Six of the ten best progenies in terms of both stability and productivity were identical to those obtained by Pupin et al. (2015), who used the Harmonic Mean of Relative Performance of Genetic Values (HMRPGV; Resende, 2007) for all E. urophylla progenies. Only one of the high ranking progeny identified by the HMRPGV was not included in the AMMI analysis conducted herein. If we compare the results of AMMI and HMRPGV methodologies, although they agree in terms of productivity, some progenies were less stable in the AMMI analysis. Because the HMRPGV method considers genotypic and non-phenotypic stability, it explores the data in different ways. Despite the differences observed, the use of varying methodologies can be 
complementary, offering robust results for the recommendation of genotypes, such as the group of progenies identified in both studies.

Biplot AMMI2 shows the first two axes in which the effects of the GxE interaction are concentrated. Itatinga and Itamarandiba exerted the least interactive effect on the progenies, since they presented shorter projections than the other experimental areas (Figure 2). The angle between the projections determines the phenotypic correlation between environments (Mohammadi and Amri, 2011). Thus, the results suggest that the environments can be divided into three specific groups: i) Uberaba, Itatinga, and Itamarandiba; ii) Anhembi; and iii) Selvíria (Figure 2). The need environmental stratification was also constated in Eucalyptus saligna in Brazil (Oliveira et al., 2018), in Pinus radiata in Australia (Ivković et al., 2015) and in Salix spp in USA and Canada, which used AMMI analysis (Fabio et al., 2017).

Genotypes with scores similar to zero and concentrated around the origin for the two IPCA axes are less sensitive to GXE interaction (Figure 2). Progenies plotted further away from the origin are more responsive and strongly influenced by the GXE interaction, which enables the identification of specific adaptations. Stability is indicative of the progenies respective adaptive amplitudes, that is, stable genotypes tend to be broadly adapted to environments (Duarte and Vencovsky, 1999). Thus, 40 progenies $(31.7 \%)$ were considered to be widely adapted and could be recommended for all five environments. Among them, we identified a group of 20 progenies (15.9\%) as having greater productivity, stability, and adaptability. In comparison with Pupin et al. (2015), only six progenies were consistent across both studies for these three characteristics. We detected a few cases of progenies with adaptation specific to an environment, including: four progenies in Itamarandiba; and one progeny each in Uberaba and Anhembi. Two progenies can be considered adapted to the environment in Selvíria, as their performance was superior to the others, although not in terms of productivity.

\section{Conclusion}

The effects of the environment and GxE interaction are more pronounced than genotype effects and should not be neglected in the process of selection. There are progenies with greater productivity and stability, although stability is not associated with productivity. The stratification of the selection in three specific environments is necessary due to the occurrence of a complex GxE interaction.

\section{References}

Adebola, P.O., Shegro, A., Laurie, S.M., Zulu, L.N., Pillay, M. (2013). Genotype x environment interaction and yield stability estimate of some sweet potato ([lpomoea batatas (L.) Lam] breeding lines in South Africa. Journal of Plant
Breeding and Crop Science 5(9):182-186.

http://dx.doi.org/10.5897/JPBCS2013.0387.

Akbarpour, O., Dehghani, H., Sorkhi, B., Gauch Jr., H.G. (2014). Evaluation of genotype $x$ environment interaction in barley (Hordeum vulgare L.) based on AMMI model using developed SAS Program. Journal of Agricultural Science and Technology 16(4):909-920. http://jast.modares.ac.ir/article 10897.html. Akter, A., Hassan, J.M., Kulsum, U.M., Hossain, K., Rahman, M.M. (2014). AMMI Biplot analysis for stability of grain yield in hibrid rice (Oryza sativa L.). Rice Research: Open Access 2(2):1-4. http://dx.doi.org/10.4172/jrr.1000126.

Assis, T.F., Muro Abad, J.I., Aguiar, A.M. (2015). Melhoramento genético do eucalipto. In: Schumacher, M.V., Vieira, M. Silvicultura do eucalipto no Brasil. Santa Maria, Brazil: Editora UFSM, 308p. ISBN: 9788573912319.

Chambel, M.R., Climent, L., Alía, R., Valladares, F. (2005). Phenotypic plasticity: a useful framework for understanding adaptation in forest species. Investigación agraria: Sistemas y recursos forestales 14(3):334-344. http://dx.doi.org/10.5424/srf/2005143-00924.

Correia, I., Alía, R., Yan, W., David, T., Aguiar, A., Almeida, M. (2010). Genotype x Environment interactions in Pinus pinaster at age 10 in a multi-environment trial in Portugal: a maximum likelihood approach. Annals of Forest Science 67(6):612-621. http://dx.doi.org/10.1051/forest/2010025.

Crossa, J. (2012). From genotype $x$ environment interaction to gene $x$ environment interaction. Current Genomics 13(3):225-244 http://dx.doi.org/10.2174/138920212800543066.

Crossa, J., Fox, P.N., Pfeifer, W.H., Rajaram, S., Gauch, H.G. (1991). AMMI adjustment for statistical analysis of an international wheat trial. Theoretical Applied of Genetics 81(1):27-37. http://dx.doi.org/10.1007/BF00226108.

Duarte, J.B., Vencovsky, R. (1999). Interação genótipos x ambientes: uma introdução a análise AMMI. Ribeirão Preto, Brazil: Sociedade Brasileira de Genética (Séries Monografias n 9), 60p.

Fabio, E.S., Volk, T.A., Miller, R.O., Serapiglia, M.J., Gauch, H.G., Van Rees, K.C.J., Hangs, R.D., Amichev, B.Y., Kuzovkina, Y.A., Labrecque, M., Johnson, G.A., Ewy, R.G., Kling, G.J., Smart, L.B. (2017). Genotype x environment interaction analysis of North American shrub willow yield trials confirms superior performance of triploid hybrids. GCB Bioenergy 9(2):445-459. https://doi.org/10.1111/gcbb.12344.

Funga, A., Tadesse, M., Eshete, M., Fikre, A., Korbu, L., Girma, N., Bekele, D., Mohamed, R., Bishaw, Z., Rao, G., Siambi, M., Monyo, E., Gaur, P., Ojiewo, C. (2017). Genotype by environment interaction on yield stability of desi type chickpea (Cicer arietinum L.) at major chickpea producing areas of Ethiopia. Australian Journal of Crop Science 11(2):212-219. http://dx.doi.org/10.21475/ajcs.17.11.02.p297.

Gauch, H.G.J. (2006). Statistical analysis of yield trials by AMMI and GGE. Crop Science 46(4):1488-1500. http://dx.doi.org/doi:10.2135/cropsci2005.07-0193.

Gauch, H.G.J., Zobel, R.W. (1997). Identifying mega-environments and targeting genotypes. Crop Science 37:311-326 http://dx.doi.org/10.2135/cropsci1997.0011183X003700020002x.

Gollob, H.F. (1968). A statistical model which combines features of factor analytic and analysis of variance techniques. Psychometrika 33(1):73-115. http://dx.doi.org/10.1007/BF02289676.

Gonçalves, J.L.M., Alvares, C.A., Higa, A.R., Silva, L.D., Alfenas, A.C., Stahl, J., Ferraz, S.F.B., Lima, W.P., Brancalion, P.H.S., Hubner, A., Bouillet, J.P.D., Laclau, J.P., Nouvellon, Y., Epron, D. (2013). Integrating genetic and silvicultural strategies to minimize abiotic and biotic constraints in Brazilian eucalypt plantations. Forest Ecology and Management 301:6-27, 2013. http://dx.doi.org/101016/jforeco201212030.

Harwood, C. (2011). New introduction - doing right. In: Developing a eucalypt resource Learning from Australia and elsewhere. Ed J Walker Wood Technology Research Centre, University of Canterbury, Christchurch, New Zealand, 125-136.

Hodge, G.R., Dvorak, W.S. (2015). Provenance variation and within- provenance genetic parameters in Eucalyptus urophylla across 125 test sites in Brazil, Colombia, Mexico, South Africa and Venezuela. Tree Genetics \& Genomes 11(3):11-57. http://dx.doi.org/10.1007/s11295-015-0889-3.

Inmet. (2017). Instituto Nacional de Meteorologia [online] Banco de dados meteorológicos para ensino e pesquisa. http://www.inmet.gov.br/portal/index.php?r=bdmep/bdmep.

Ivković, M., Gapare, W., Yang, H., Dutkowski, G., Buxton, P., Wu, H. (2015). Pattern of genotype by environment interaction for radiate pine in southern Aus- 
tralia. Annals of Forest Science 72(3):391-401. http:// http://dx.doi.org/10.1007/s13595-014-0437-6.

Lemon, J. (2006). Plotrix: a package in the red light district of R. R-News, New York 6(4):8-12.

Li, Y., Suontana, M., Burdon, R.D., Dungey, H.S. (2017). Genotype by environment interactions in forest tree breeding: review of methodology and perspectives on research and application. Tree Genetics \& Genomes 13(60):1-18. https://doi.org/10.1007/s11295-017-1144-X.

Martinez, D.T., Resende, M.D.V., Costa, R.B., Higa, A.R., Santos, G.A.S., Fier, I.S.N. (2012). Study of the interaction genotype $x$ environment in progenies of $\mathrm{Pi}$ nus taeda by means of the analysis of genetic parameters. Floresta 42(3):539-552.

Melo, E.A.S.C.D., Gonçalves, J.L.M., Rocha, J.H.T., Hakamada, R.E., Bazani, J.H., Wenzel, A.V.A., Ferreira, E.V.D.O., Ferraz, A.V. (2015). Responses of clonal eucalypt plantations to $\mathrm{N}, \mathrm{P}$ and $\mathrm{K}$ fertilizer application in different edaphoclimatic conditions. Forests 7(2):1-15. https://doi.org/10.3390/f7010002.

Mendiburu, F. (2013). Agricolae: statistical procedures for agricultural research. [S.l.:s.n., 200-]

Mitrovic, B., Stanisavljevi, D., Treski, S., Stojakovic, M., Ivanovic, M., Bekavac, G., Rajkovic, M. (2012). Evaluation of experimental maize hybrids tested in multi-location trial using AMMI and GGE biplot analysis. Turkish Journal of Field Crops 17(1):35-40

Mohammadi, R., Amri, A. (2011). Graphic analysis of trait relations and genotype evaluation in durum wheat. Journal of Crop Improvement 25(6):680-696. https://doi.org/10.1080/15427528.2011.601437.

Mustapha, M., Bakari, H.R. (2014). Statistical evaluation of genotype by environment interactions for grain yield in millet (Penniisetum glaucum (L.) R. Br.). The International Journal of Engineering and Science 3(9):7-16. http://www.theijes.com/papers/v3-i9/Version-1/B039107016.pdf.

Namkoong, G., Snyder, E.B., Stonecypher, R. (1966). Heritability and gain concepts for evaluating breeding systems such as seedling orchards. Silvae Genetica 15:76-84.

https://www.thuenen.de/media/institute/fg/PDF/Silvae_Genetica/1966/ Vol. 15 Heft 3/15 3 76.pdf

Nunes, A.C.P., Santos, G.A., Resende, M.D.V., Silva, L.D., Higa, A., Assis, T.F. (2016). Estabelecimento de zonas de melhoramento para clones de eucalipto no Rio Grande do Sul. Scientia Forestalis 44(111):563-574. https://doi.org/10.18671/scifor.v44n111.03.

Oliveira, T.W.G., De Paula, R.C., Moraes, M.L.T., Alvares, C.A., Miranda, A.C., Silva, P.H.M. (2018). Stability and adaptability for wood volume in the selection of Eucalyptus saligna in three environments. Pesquisa Agropecuária Brasileira 55 (In Press).

Pinto, D.S., Resende, R.T., Mesquita, A.G.G., Rosado, A.M., Cruz, C.D. (2014). Early selection in tests for growth traits of Eucalyptus urophylla clones test. Scientia Forestalis 42(102):251-257.

Pupin, S., Santos, A.V.A., Zaruma, D.U.G., Miranda, A.C., Silva, P.H.M., Marino, C.L., Sebbenn, A.M., Moraes, M.L.T. (2015). Productivity, stability and adaptability in open pollination progenies of Eucalyptus urophylla S.T. Blake. Scientia Forestalis 43(105):127-134.

Rao, P.S., Reddy, P.S., Rathore, A., Reddy, B.V.S., Panwar, S. (2011). Application GGE biplot and AMMI model to evaluate sweet sorghum (Sorghum bicolor) hybrids for genotype $x$ environment interaction and seasonal adaptation. Indian Journal of Agricultural Sciences 81(5):438-444. https://core.ac.uk/download/pdf/12102139.pdf.

R, Development Core Team. (2011). R: A Language and Environment for Statistical Computing. Vienna, Austria: R Foundation for Statistical Computing ISBN: 3900051070. http://www.R-project.org/.

Resende, M.D.V. (2007). Software SELEGEN - REML/BLUP: sistema estatístico e seleção genética computadorizada via modelos lineares mistos. Colombo, Brazil: Embrapa Florestas, 359p. ISBN 9788589281164.

Scanavaca Júnior, L., Garcia, J.N. (2003). Potential for genetic improvement in Eucalyptus urophylla from the Island Flores. Scientia Forestalis 64:23-32.

Silva, P.H.M., Marco, M., Alvares, C.A., Miranda, A.C., Lee, D.J., Moraes, M.L.T., De Paula, R.C. (2018). Early selection of Eucalyptus grandis families across environmental conditions (In Press).

Silva, P.H.M., Poggiani, F., Libardi, P.L., Gonçalves, A.N. (2013). Fertilizer management of eucalypt plantations on sandy soil in Brazil: initial growth and nutrient cycling. Forest Ecology and Management 301:67-71. https://doi.org/10.1016/j.foreco.2012.10.033.
Vencovsky, R., Barriga, P. (1992). Genética biométrica no fitomelhoramento. Ribeirão Preto, Brazil: Sociedade Brasileira de Genética, 496p.

Vencovsky, R., Ramalho, M.A.P., Toledo, F.H.R.B. (2012). Contribution and perspectives of quantitative genetics to plant breeding in Brazil. Crop Breeding and Applied Biotechnology 12:7-14. http://dx.doi.org/10.1590/S1984-70332012000500002.

Verissimo, M.A.A., Silva, S.D.A., Aires, R.F., Daros, E., Panziera, W. (2012). Adaptability and stability of early sugarcane genotypes in Rio Grande do Sul, Brazil. Pesquisa Agropecuária Brasileira 47(4):561-568. http://dx.doi.org/10.1590/S0100-204X2012000400012.

Zobel, R.W., Wright, M.J., Gauch, H.G.J. (1988). Statistical analysis of a yield trial. Agronomy Journal 80(3):388-393. http://dx.doi.org/10.2134/agronj1988.00021962008000030002x.

Weihs, C., Ligges, U., Luebke, K., Raabe, N. (2005). klaR Analyzing German business cycles. In: Baier D, Decker R, Schmidt-Thieme L (Ed.). Data analysis and decision support. Berlin, Germany: Springer Berlin Heidelberg, p.335-343. https://doi.org/10.1007/3-540-28397-8 36.

Yan, W., Kang, M.S. (2002). GGE biplot analysis: A graphical tool for breeders, geneticists, and agronomists. Florida, United States: CRC press. 288p. ISBN 0849313384.

Yan, W., Pageau, D., Frégeau Reid, J., Durand, J. (2011). Assessing the representativeness and repeatability of test locations for genotype evaluation. Crop Science 51(4):1603-1610. http://dx.doi.org/10.2135/cropsci2011.01.0016. 